\title{
High prevalence of t895 and t9364 spa types of methicillin-resistant Staphylococcus aureus in a tertiary-care hospital in Mexico: different lineages of clonal complex 5
}

C. Negrete-González ${ }^{1}$, E. Turrubiartes-Martínez ${ }^{1,2}$, O. G. Galicia-Cruz³ , D. E. Noyola ${ }^{4}$, G. Martínez-Aguilar ${ }^{5}$,

L. F. Pérez-González ${ }^{6}$, R. González-Amaro ${ }^{7}$ and P. Niño-Moreno ${ }^{1,8^{*}}$ (D)

\begin{abstract}
Background: Staphylococcus aureus is a leading cause of broad-spectrum infections both in the community and within healthcare settings. Methicillin-resistant Staphylococcus aureus (MRSA) has become a global public health issue. The aim of this study was to examine the clinical and molecular characteristics of Staphylococcus aureus isolates and to define the population structure and distribution of major MRSA clones isolated in a tertiary-care hospital in Mexico.

Results: From April 2017 to April 2018, 191 Staphylococcus aureus isolates were collected. The frequency of MRSA was 26.7\%; these strains exhibited resistance to clindamycin (84.3\%), erythromycin (86.2\%), levofloxacin (80.3\%), and ciprofloxacin (86.3\%). The majority of MRSA strains harbored the SCCmec type II (76.4\%) and t895 (56.8\%) and t9364 (11.7\%) were the most common spa types in both hospital-associated MRSA and community-associated MRSA isolates. ST5-MRSA-II-t895 (New York /Japan clone) and ST1011-MRSA-II-t9364 (New York /Japan-Mexican Variant clone) were the most frequently identified clones. Furthermore, different lineages of Clonal Complexes 5 (85.4\%) and 8 (8.3\%) were predominantly identified in this study.

Conclusion: Our study provides valuable information about the epidemiology of MRSA in a city of the central region of Mexico, and this is the first report on the association between t895 and t9364 spa types and ST5 and ST1011 lineages, respectively. These findings support the importance of permanent surveillance of MRSA aimed to detect the evolutionary changes of the endemic clones and the emergence of new strains.
\end{abstract}

Keywords: Methicillin-resistant Staphylococcus aureus, Spa-typing, SCCmec type II, Clonal complex 5-ST1011, Spa type t895, Spa type t9364, New York/Japan-Mexican variant clone

\footnotetext{
* Correspondence: ncarmenp@uaslp.mx

'Sección de Genómica Médica, Centro de Investigación en Ciencias de la

Salud y Biomedicina, Universidad Autónoma de San Luis Potosí, San Luis Potosí, Mexico

${ }^{8}$ Laboratorio de Genética, Facultad de Ciencias Químicas, Universidad Autónoma de San Luis Potosí, San Luis Potosí, Mexico

Full list of author information is available at the end of the article
}

(C) The Author(s). 2020 Open Access This article is licensed under a Creative Commons Attribution 4.0 International License, which permits use, sharing, adaptation, distribution and reproduction in any medium or format, as long as you give appropriate credit to the original author(s) and the source, provide a link to the Creative Commons licence, and indicate if changes were made. The images or other third party material in this article are included in the article's Creative Commons. licence, unless indicated otherwise in a credit line to the material. If material is not included in the article's Creative Commons licence and your intended use is not permitted by statutory regulation or exceeds the permitted use, you will need to obtain permission directly from the copyright holder. To view a copy of this licence, visit http://creativecommons.org/licenses/by/4.0/. The Creative Commons Public Domain Dedication waiver (http://creativecommons.org/publicdomain/zero/1.0/) applies to the data made available in this article, unless otherwise stated in a credit line to the data. 


\section{Background}

Staphylococcus aureus (S. aureus) is a commensal and a pathogen in humans; approximately $30-50 \%$ of the population are transient nasal carriers and $10-20 \%$ of individuals are persistently colonized with this organism $[1,2]$. Furthermore, colonization of the skin or mucosa with $S$. aureus may increase the risk of invasive infections [3]. In addition, $S$. aureus has been recognized as an extremely versatile pathogen in humans, causing three major syndromes: superficial lesions, such as impetigo and skin wound infections; deep and systemic infections, such as osteomyelitis, endocarditis, pneumonia, and bacteremia; and toxemic infections, such as toxic shock syndrome, scalded skin syndrome, and food poisoning [4].

In 1961, one year after the introduction of methicillin into medical practice, the first methicillin-resistant Staphylococcus aureus (MRSA) strain was identified; methicillin resistance is mediated by the Staphylococcal Cassette Chromosome mec (SCCmec) genetic element [5]. This element includes the mec and $\mathrm{ccr}$ gene complexes, which are flanked by three junkyard regions. SCCmec is inserted into a unique site of the bacterial chromosome by the action of Ccr proteins (encoded by the $c c r$ gene complex), which induce the specific recombination between the attB sequence at the 3 ' end and the attS homologous sequence of SCCmec [6]. Variations in the genetic content and structural organization of these elements result in 13 different types and subtypes of SCCmec [7-9].

An increasing number of MRSA strains were identified initially in hospital centers (HA-MRSA) and, several years later, cases of community-associated MRSA infections (CA-MRSA) were reported. In this regard, the epidemiology of MRSA infections has changed significantly with the global emergence and expansion of CA-MRSA strains [10].

The most frequently reported MRSA isolates belong to major Clonal Complexes (CC) CC1, CC5, CC8, CC22, CC30, CC45, and CC80 [11-13]. The most representative HA-MRSA clones are ST5-I/EMRSA-3/CordobesChilean and ST5-II/USA100/New York/Japan clones (CC5), ST36-II/USA200 clone (CC30), ST45-II/USA600 clone (CC45), and ST239 III/ Brazilian/Hungarian clone (CC8), while the most representative CA-MRSA are ST1-IV/USA400 (CC1), ST5-IV/Pediatric clone (CC5), ST8-IV/USA300 and USA300-LA variant (CC8), EMRSA-15 clone (CC22), ST30-IV/Southwest Pacific clone (CC30), and ST80-IV/European clone (CC80) [12, 14]. The distribution of these clones varies in different countries and regions of the world; in Mexico, ST5-II/ New York Japan and USA300 clones have been described [15, 16].

According to the World Health Organization (WHO), global surveillance of MRSA is essential for the identification of international transmission routes and the subsequent development of effective prevention and control strategies of this pathogen [17]. For this purpose, molecular typing methods are a valuable tool for the successful characterization of $S$. aureus isolates. In this regard, Next Generation Sequencing (NGS) has been used to identify $S$. aureus CCs and is considered the best laboratory technique for identification of DNA diversity in any organism. However, this methodology remains technically demanding and requires robust software to analyze the results [12]. Traditional typing methods include Multiple Locus Sequence Typing (MLST), PulsedField Gel Electrophoresis (PGFE), and spa-typing. MLST is a great tool for evolutionary investigations and strain identification and is based on the allelic profile of the seven housekeeping genes. PFGE is based on the digestion of DNA with restriction endonucleases and the detection of the banding patterns. Although these two methods show a high discriminatory power, they are laborious and require intra-laboratory standardization protocols [12]. On the other hand, spa-typing is based on the detection of sequence variation in repeats at the $\mathrm{X}$ region of the staphylococcal protein A spa gene. This typing technique exhibits high discriminatory power, has a standardized nomenclature, is cost-effective, and shows an excellent reproducibility. Spa-typing can be used for the investigation of hospital outbreaks and to analyze the evolution of S. aureus [18]. However, this methodology has some limitations, mainly in regions where a particular clone or a small number of clones are endemic $[11,19]$.

The aim of this study was to estimate the prevalence of MRSA and to analyze the molecular characteristics, and antibiotic resistance profiles of CA- and HA-MRSA genotypes in San Luis Potosi, a large city (approximately 1.1 million inhabitants) in the center of Mexico.

\section{Results \\ Sample collection}

$S$. aureus strains were obtained from one hundred ninety-one patients from the emergency department $(n=62)$, surgery $(n=47)$, intensive care unit $(n=31)$, internal medicine $(n=35)$, gynecology $(n=6)$, burn unit $(n=2)$, and outpatient service $(n=8)$; patients in whom samples were obtained in the outpatient service were subsequently admitted to the hospital. The clinical specimens were obtained from infections in skin and soft tissues $(n=79)$, respiratory tract $(n=53)$, blood $(n=36)$, bone and joints $(n=20)$, and cerebrospinal fluid $(n=3)$. Seventy-seven percent (147 out of 191) of strains were considered as HA and $23 \%$ (44 out of 191) were classified as CA.

One hundred fourteen patients were male and seventy-seven were female. Forty isolates were identified 
in children, and 151 in adults. The median age was 44 years. The mean length of hospital stay was $18.4 \pm 19.5$ days (range 1-105 days). Table 1 shows comorbidities, surgical procedures, and history of hospital admission in the last two years before infection of participants in the study. The majority of patients $(84.4 \%)$ were discharged due to clinical improvement, $2 \%$ of patients were transferred to another hospital, $1.6 \%$ of patients requested voluntary discharge, and $11.5 \%$ of patients infected with S. aureus died.

Ten $(45.5 \%)$ of the 22 patients who died had an MRSA infection compared to $41(24.3 \%)$ of the 169 patients who survived $(P=0.034)$. Patients who died were also older (mean 46.3 years) than those who survived (mean 35.2 years; $P=0.034$ ). In contrast, there were no significant differences in the prevalence of underlying conditions (such as diabetes, malignancy, or renal disease) between patients with a fatal outcome and those who did not die (Additional file 1: Table S1).

Table 1 Clinical and demographic characteristics of the patients with $S$. aureus infection included in the study

\begin{tabular}{|c|c|c|}
\hline & $\boldsymbol{N}=191$ & (\%) \\
\hline \multicolumn{3}{|l|}{ Sex } \\
\hline Male & 114 & 59.7 \\
\hline Female & 77 & 40.3 \\
\hline \multicolumn{3}{|l|}{ Age (years) } \\
\hline Infants $0-1$ & 12 & 6.2 \\
\hline Children 2-10 & 13 & 6.8 \\
\hline Adolescents 11-17 & 15 & 7.8 \\
\hline Young adults 18-35 & 59 & 30.9 \\
\hline Adults $36-60$ & 62 & 32.5 \\
\hline Seniors $>60$ & 30 & 15.7 \\
\hline \multicolumn{3}{|l|}{ Length of stay (days) } \\
\hline Mean & 18.45 & \\
\hline SD & 19.52 & \\
\hline Range & $1-105$ & \\
\hline \multicolumn{3}{|l|}{ Underlying disease } \\
\hline Diabetes mellitus & 51 & 26.7 \\
\hline Hypertension & 45 & 23.6 \\
\hline Renal disease & 21 & 11 \\
\hline Neoplasms & 10 & 5.2 \\
\hline Surgical procedures & 84 & 44 \\
\hline Prior hospitalization & 135 & 70.7 \\
\hline \multicolumn{3}{|l|}{ Hospital discharge } \\
\hline Clinical improvement & 162 & 84.4 \\
\hline Death & 22 & 11.5 \\
\hline Transfer & 4 & 2.1 \\
\hline Voluntary discharge & 3 & 1.6 \\
\hline
\end{tabular}

\section{Identification of MRSA strains}

The $m e c A$ gene was detected in 51 out of 191 isolates (26.7\%), and 45 of them showed resistance to oxacillin and were positive on cefoxitin-based screening. The study was carried out between epidemiological week (as defined by WHO) 14, 2017 and epidemiological week 17, 2018. The weekly number of $S$. aureus infections varied between 1 and 8 cases. As shown in Fig. 1, the largest number of cases was observed at week 37 (eight, two of them MRSA), whereas in weeks $25,35,38,50,9$ and 12 , six cases were identified. Moreover, the highest weekly number of MRSA cases was 4, in weeks 38 and 41, followed by weeks 20,50, and 9 with 3 cases. Two MRSA cases were identified in weeks 18, 19, 23, 37, $39,45,46,48,5$, and 13 , whereas a single case was detected in weeks $14,15,17,21,25,26,29,34,35$, $42,51,6,8,11,12$, and 14. No MRSA isolates were observed during weeks $16,22,24,27,28,30-33,36$, $40,43,44,47,49,52,1-4,7,10,15-17$. Three different periods of MRSA detection were identified during the study. The first period occurred between weeks 14 and 29 (2017), the second between weeks 34 and 51(2017), and the third between weeks 5 and 14. (2018) Fig. 1.

\section{Antimicrobial susceptibility}

The antibiotic resistance pattern differed significantly between MRSA and MSSA isolates $(P<0.001$ in most cases). Thus, most MRSA strains showed resistance to clindamycin (84.3\%), erythromycin (86.2\%), levofloxacin $(80.3 \%)$, and ciprofloxacin (86.3\%), with low resistance to gentamicin (13.7\%) and rifampin (9.8\%). In contrast, MSSA strains showed minimal resistance to clindamycin (7.1\%), erythromycin (9.3\%), ciprofloxacin (3.5\%), levofloxacin (1.4\%), and gentamicin (1.4\%). None of MRSA or MSSA strains were resistant to vancomycin, linezolid, tigecycline, trimethoprim/sulfamethoxazole, and tetracycline (Table 2). Additional file 2: Table S2, shows the minimum inhibitory concentration for each antibiotic.

\section{SCCmec typing}

Thirty-nine MRSA strains were classified as SCCmec type II (four CA-MRSA, and thirty-five HA-MRSA) and the SCCmec subtype IIb was identified in four strains (HA-MRSA). Two isolates harbored SCCmec type IVc/E and SCCmec type IVa was identified in one isolate (one CA-MRSA and two HA-MRSA). In five isolates it was not possible to identify the SCCmec types.

\section{Spa-typing}

MRSA isolates were classified in 11 different spa types, including t895 $(n=29,56.8 \%)$, t9364 $(n=6,11.7 \%)$, t008 $(\mathrm{n}=2,3.9 \%), \mathrm{t} 003(n=3,5.8 \%), \mathrm{t} 4229, \mathrm{t} 002, \mathrm{t} 012, \mathrm{t} 040$, 


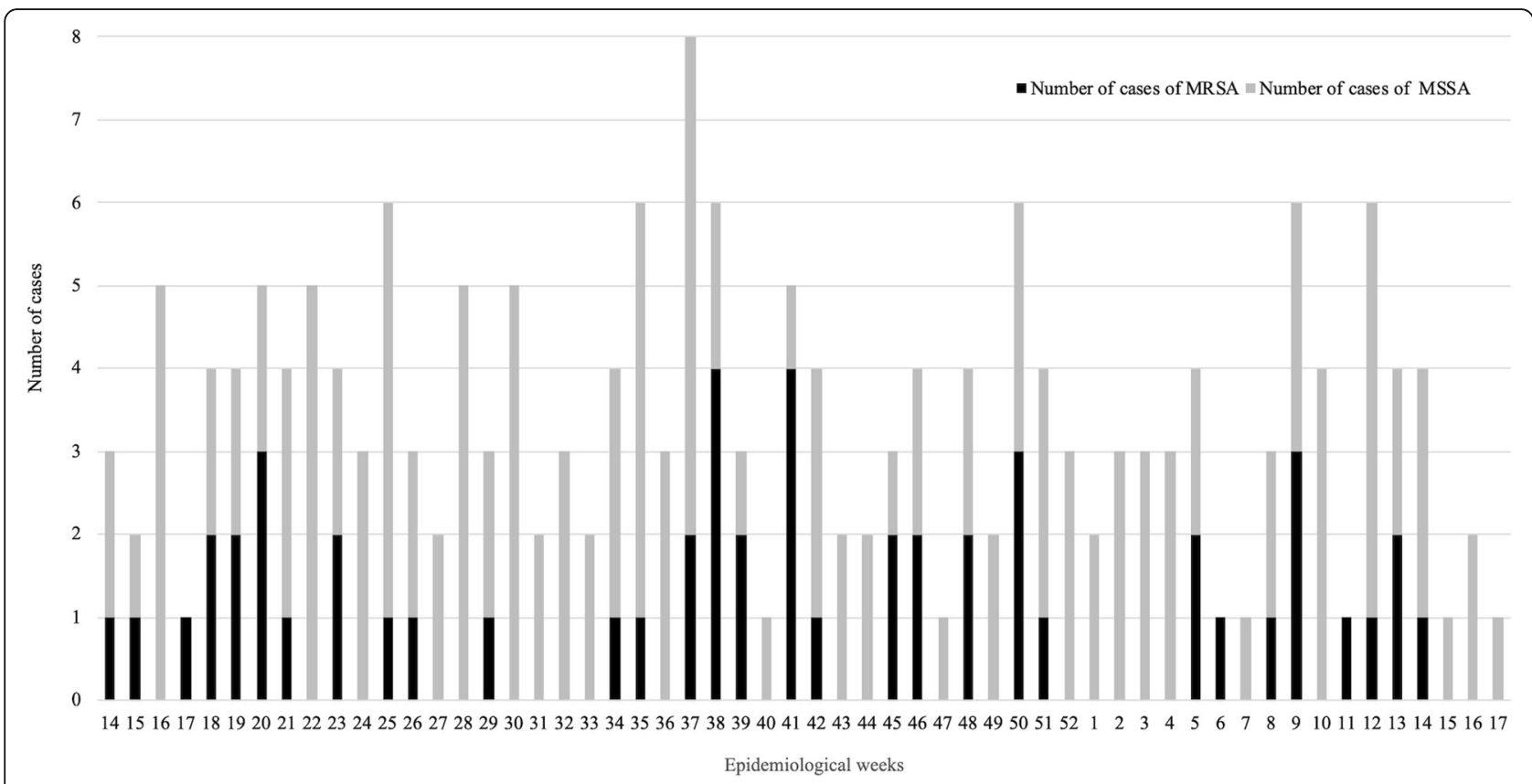

Fig. 1 Number of cases of S. aureus infection in each epidemiological week. Black bars correspond to MRSA isolates and grey bars to MSSA strains

t304, t111, and t509 $(n=1)$. The spa type t895 was the most common spa type among HA-MRSA and CAMRSA isolates. In one strain, we identified a spa type not previously reported (spa type unknown). In three isolates, the PCR employed by us did not amplify the spa gene.

Table 2 Antibiotic resistant pattern of MSSA and MRSA isolates MSSA $\boldsymbol{N}=140 \quad$ MRSA $\boldsymbol{N}=51 \quad P$

\begin{tabular}{llll} 
Antibiotic & $(\mathrm{n} / \%)$ & $(\mathrm{n} / \%)$ & \\
\hline Benzylpenicillin & $109(77.8)^{\mathrm{a}}$ & $51(100)$ & \\
Clindamycin & $10(7.1)$ & $43(84.3)$ & $<0.001$ \\
Erythromycin & $13(9.3)$ & $44(86.2)$ & $<0.001$ \\
Levofloxacin & $2(1.4)$ & $41(80.3)$ & $<0.001$ \\
Ciprofloxacin & $5(3.5)$ & $44(86.3)$ & $<0.001$ \\
Moxifloxacin & $0(0)$ & $18(35.2)$ & $<0.001$ \\
Rifampin & $0(0)$ & $5(9.8)$ & 0.001 \\
Gentamicin & $2(1.4)$ & $7(13.7)$ & 0.002 \\
Oxacillin & $0(0)$ & $45(88.2)$ & $<0.001$ \\
Vancomycin & $0(0)$ & $0(0)$ & $\mathrm{NA}$ \\
Tetracyclin & $0(0)$ & $0(0)$ & $\mathrm{NA}$ \\
Linezolid & $0(0)$ & $0(0)$ & $\mathrm{NA}$ \\
Tigecycline & $0(0)$ & $0(0)$ & $\mathrm{NA}$ \\
Trimethoprim/sulfametoxazole & $0(0)$ & $0(0)$ & $\mathrm{NA}$ \\
\hline
\end{tabular}

${ }^{a}$ The penicillinase test was not performed in the 31 benzylpenicillin susceptible MSSA isolates

\section{Dendrogram of MRSA strains}

A dendrogram was constructed to analyze the relation among S. aureus strains based on their spa type (Fig. 2). The spa type t895 (cluster 1) was identified in twentynine isolates in patients from the surgery ward $(n=15)$, emergency department $(n=4)$, internal medicine $(n=3)$, intensive care unit $(n=1)$, and outpatient service $(n=1)$. In children, t895 was identified in the pediatric ward $(n=4)$ and neonatal intensive care unit $(n=1)$. Twentyseven isolates harbored the SCCmec type II, one isolate harbored SCCmec type IIb, and in one strain the SCCmec type was not identified. Twenty-seven isolates of this cluster showed resistance to beta-lactams, fluoroquinolones (levofloxacin and ciprofloxacin), clindamycin, and erythromycin. The B-796 strain was rifampinresistant, and the B-766 strain was gentamicin-resistant. The origin of MRSA strains in this cluster was predominantly HA-MRSA $(n=27)$, and only two cases were CA-MRSA (C-706 and C-708); the latter isolates were identified in the surgery ward, in weeks 13 and 14. In this cluster seven patients died.

The cluster 2 (t9364) included six isolates, three from the surgery ward and one from the intensive care unit, the burn unit and the internal medicine ward. Five isolates in this cluster harbored the SCCmec type II, and one the SCCmec type IIb; strains from both SCC types showed resistance to fluoroquinolones, clindamycin, and erythromycin. Four of these strains (A-747, A-786, B713 , and B-773) were resistant to rifampin, and another 


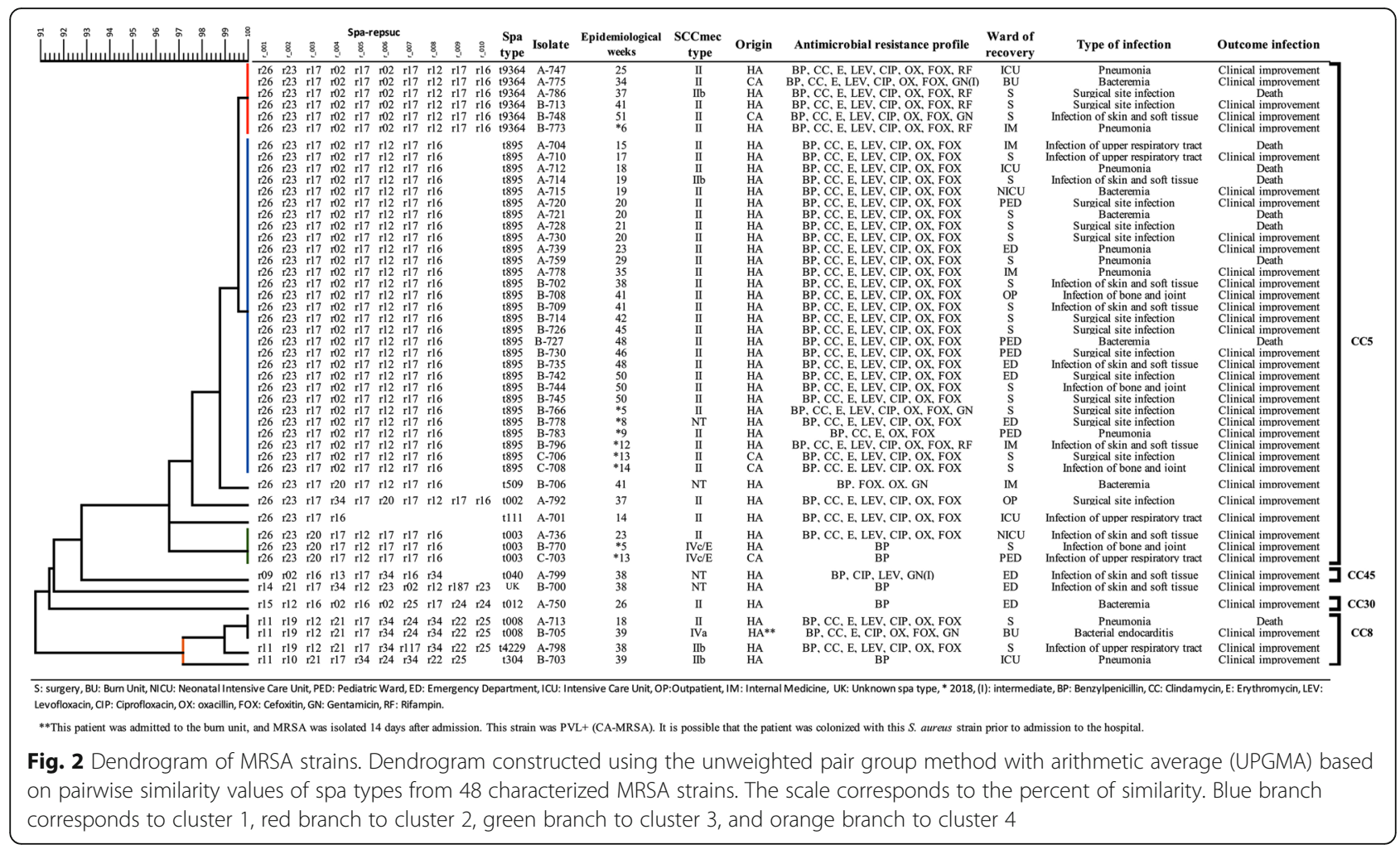

(B-748) to gentamicin. The percent of similarity between spa types $\mathrm{t} 895$ and $\mathrm{t} 9364$ was $99.5 \%$. The A-792 (t002) and B-706 (t509) isolates showed more than 98\% of similarity with $\mathrm{t} 985$ and $\mathrm{t} 9364$, and A-701 (t111) showed $97.6 \%$ of similarity to spa types t895, t9364 and t003.

The cluster 3 (t003) included three isolates, two of them were detected in children (A-736 and C-703), and one (B-770) from a patient in the surgery ward. In this group, two isolates harbored SCCmec type $\mathrm{IVc} / \mathrm{E}$ and were resistant to beta-lactams. In the other isolate we identified SCCmec type II.

The spa type t040 had a $92.7 \%$ similarity with the spa types t895, t9364, t003 and t002, and had 91.5\% similarity with an unknown spa type that was identified in B700. This strain was only resistant to beta-lactams.

The cluster 4 had $90.8 \%$ similarity with the previously mentioned spa types. This cluster included four isolates with t008, t4229 and t304 spa types. Two patients from the surgery and burn wards were infected with HAMRSA-t008, A-713 strain was isolated in the eighteen week and harbored the SCCmec type II, and B-705 was isolated in the thirty-nine week and harbored the SCCmec type IVa.

\section{Multilocus sequence typing}

Spa types t895 and t9364, the major spa types identified in this study, have not previously been associated to sequence types (ST). In order to analyze this, we selected six isolates, and these were identified as ST1011 $(n=4)$ and ST5 $(n=2)$. The association analysis of spa types of clusters 3 to 4 with ST was performed in the Spa server.

\section{Discussion}

In the present study, we have assessed the epidemiological characteristics of $S$. aureus isolates during one year of intra-hospital surveillance and we analyzed the molecular characteristics of MRSA strains. The most frequent $S$. aureus infections were those affecting the skin and soft tissues $(n=48,25.1 \%)$ and bacteremia $(n=31$, $17 \%)$. In contrast, the most frequent type of infection caused by MRSA isolates was surgical site infection $(n=$ $14,27 \%)$.

The mortality associated with staphylococcal infections in our study (11.5\%) was lower than that previously reported (approximately 15 years ago) in Mexico (50\%) [20]. MRSA infections were detected more frequently in fatal cases than in patients who survived. Study participants who died were also older than those who survived. Of note, while the presence of underlying diseases, history of surgical procedures, and health-care exposure have previously been reported to be associated with fatal infections [21,22], we did not find significant differences for these conditions between patients who died and those who survived.

The recent epidemiology of $S$. aureus has focused on the increase and spread of MRSA strains in the 
healthcare setting and the community. In Denmark and Scandinavian countries the prevalence of MRSA is less than $1 \%$. In contrast, in the east and southeast of Europe, the prevalence of MRSA is greater than 30\% [22]. Peru has the highest reported prevalence in Latin America (80\%) [17]. In Mexico, there are a limited number of studies about MRSA and the available information shows an increase in the prevalence of MRSA ranging from 7 to 53\% between 1989 and 2017 [15, 23-25]. In our study, the prevalence of MRSA identified by molecular methods was higher than the prevalence identified by the oxacillin resistance phenotype, which has been the most used method in our country $[17,25,26]$. The $26.7 \%$ prevalence registered in our study is higher than that reported, between January and June 2018, in 47 hospitals in 20 states of Mexico (21.4\%) [26], a study that did not include information from the state of San Luis Potosi. In a previous study, performed between 2005 and 2006 in six Mexican hospitals, the prevalence of MRSA ranged from 1 to $43 \%$. The highest prevalence was recorded at the Hospital Central Dr. Ignacio Morones Prieto (HCIMP) [27]. In 11 years, the prevalence of MRSA decreased to $26.7 \%$ in this hospital. This fact can be explained by the infection control actions implemented. A study that highlights the importance of intrahospital surveillance of MRSA was carried out between January 1997 and May 2003 at the Pediatric Hospital of the Centro Medico Nacional-Siglo XXI (Mexico City). At this hospital, the annual frequency of methicillin resistance ranged from 17 to 23\% between 1997 and 2001, and dramatically decreased in 2002 (4\%) and 2003 (0\%), due to the intervention of the infection control committee at the end of 2001 [28].

Until February 2020 the Spa server has recorded 19, 255 different spa types [29]. According to a literature review, in the last decade, the spa types t032/t008/t002 are the most prevalent in Europe, t037/t002 in Asia, t008/ t002/t242 in America, t037/t084/t064 in Africa, and t020 in Australia [5]. Interestingly, in our study the prevalence of the spa types commonly described in America was lower than expected, and we mainly detected the spa types $\mathrm{t} 895$ and $\mathrm{t} 9364$.

Compared to other spa types, t895 has a low frequency (0.01\%); however, in the last two years its detection has increased. Between 2017 and 2019, eight strains were reported in USA and another in Germany, according to the Spa Server [29]. Although data is scarce, previous reports have associated the 895 spa type with CC5 [30]. In this regard, our data suggest an apparent association between 895 spa type and the ST5 lineage of CC5. In 97\% of the MRSA-t895 isolates, the SCCmec type II cassette was identified; these molecular characteristics correspond to the New York / Japan/ USA100 clone [15]. However, a limitation of this study is that the sequence types (MLST) of several of the 1895 strains were not determined, which precluded a proper statistical analysis. Of note, SCCmec type I, type II, and type IV have been reported previously in MRSA-t895 strains [31].

The identification of 1895 as the predominant spa type in our study is of relevance, since this may have clinical and epidemiological implications. Of interest, characterization of 21 MRSA strains isolated in Estado de Mexico (Mexico) in 2013 also showed t895 to be the predominant spa type, accounting for $76.2 \%$ of isolates [31]. In a study conducted in the United States, t895 spa type was predictive for the weakbiofilm producing phenotype, compared to t008 spa type, which was identified as a predictor of the strong-biofilm producing phenotype [30].

The spa type t9364 was registered in 2011 and corresponded to a strain detected in Mexico, in a region outside of the state of San Luis Potosi [29]. In this regard, our data describe, for the first time, the association between the t9364 spa type and the ST1011 sequence type. Sequence type ST1011 was registered in the MLST database in 2006; the first report of this ST included four clinical MRSA isolates which differed from the sequence type ST 5 by the replacement of a nucleotide in the $\operatorname{arcC}$ gene. Three of these MRSA ST1011 isolates were identified at HCIMP and one at General Hospital of Durango [27]. Between 2008 and 2017, 14 isolates have been reported with the sequence type ST1011 and the SCCmec type II $[15,16]$; all of these isolates have been identified in Mexico. In 2017, ST1011-II was classified as the New York / Japan clone because of its similarity to ST5-II [15], and in a subsequent phylogenetic analysis of CC5, it was observed that the clones identified in Mexico were grouped in a subclade that was subdivided into two subclades: ST5-II and ST1011-II. This suggests that ST1011-II is not a New York/ Japan clone, but it may be a variant of it that originated in the late 1990s, the period when the CC30 was replaced in Mexico [16]. In all, available data suggests that ST1011-II-t9364 may be a Mexican variant of the New York / Japan clone which has increased in prevalence in the last 11 years; however, more studies are required to determine the differences with ST5-IIt895 [16].

Other spa types identified with lower frequency in this study corresponded to t111, t509, t003, t012, t040, t4229, and t304. The spa type t003 has been related to ST225 and ST270 sequence types, which are part of CC5 and includes the Rhine Hesse, EMRSA-3 and New York/Japan clones [32]. In addition, the spa types t012 and t040 have been identified in strains belonging to CC30 and CC45, respectively. Furthermore, the spa types $\mathrm{t} 4229$ and t304 have been associated with ST8, ST247, ST250, and ST254 sequence types, which belong 
to CC8 and include the USA300, ORSA IV and Archaic/ Iberian clones [33].

Diverse lineages of CC5 were predominant in our study. These strains are characterized by bearing the SCCmec I, II, and IV type cassettes with subtypes IVa, $\mathrm{IVC} / \mathrm{E}$, and IVg. In this regard, different studies have shown that most strains of this CC are multi-resistant, mainly to fluoroquinolones, aminoglycosides, macrolides, lincosamides, and streptogramins (as we detected in the isolates of our study), except for those that carry the IVc/E cassette that only show resistance to betalactams [15]. Moreover, to determine the relationship between MRSA strains, we classified them into clusters and analyzed their clinical and molecular characteristics. In this analysis, clusters 1 and 2 were distributed in all areas of the hospital within the three periods described previously; in this regard, it is possible that these three periods could be due to different introductions of clones into the hospital or be a consequence of intra-hospital transmission [34]. Although these two possibilities are plausible, the last one could have resulted from transfer of patients between different hospital wards during their stay. Moreover, all strains grouped in these two clusters were multi-resistant, and the highest number of deaths was recorded in cluster 1 . Furthermore, most strains in cluster 3 were only resistant to beta-lactams and the methicillin resistance phenotype was not identified. Finally, three out of four isolates in cluster 4 were identified in weeks 38 and 39, the epidemiological weeks with the highest number of $S$. aureus infections. The use of efficient and accurate epidemiological typing methods is a requisite for monitoring the spread of epidemic clones within and between hospitals. In this case, spa-typing was a good tool for differentiate into CC5 lineages, because $\mathrm{t} 895$ and $\mathrm{t} 9364$ are not widespread spa types [19]. It is worth mentioning that if t895 and t9364 clones become endemic and spread to multiple regions of Mexico, the discriminating power of spa-typing to analyze nosocomial transmission would decrease. To overcome this limitation, recent studies suggest the use of a combination of different typing techniques to increase the ability to discriminate isolates [35].

In our study, all $S$. aureus strains were susceptible to tetracycline, doxycycline and minocycline [36], and trimethoprim-sulfamethoxazole. This observation is of relevance, since these are alternatives for ambulatory treatment of MRSA infections, such as skin and soft tissue infections [37]. In contrast, tetracycline resistance was reported in $6 \%$ of MSSA strains and $17 \%$ of MRSA strains collected globally between 1997 and 2016 [38]. Resistance to this antibiotic in $S$. aureus is encoded by the tet $\mathrm{K}$ and tet $\mathrm{M}$ genes [39], mainly detected in SCCmec III, IV, and V MRSA strains [9, 40, 41]. The majority of MRSA strains in our study had SCCmec type
II, and this might explain, in part, the absence of tetracycline resistance.

\section{Conclusions}

Our data indicate that the most prevalent clones in all areas of our hospital were ST5-MRSA-II-t895 (New York /Japan clone) and ST1011-MRSA-II-t9364 (New York/Japan-Mexican Variant clone), which belong to CC5. In the HCIMP, the dominance of two CC5 lineages is evident; however, MRSA isolates with molecular characteristics consistent with Irish (weeks 18, 38 and 39), USA300 (week 39) and Pediatric (week 13) clones, that are considered epidemic MRSA clones, were identified. We consider that this study further supports continuous molecular monitoring of $S$. aureus infections as a valuable tool for epidemiological surveillance of MRSA since it allows the evaluation of evolutionary changes of endemic clones and the introduction of emerging clones that can cause hospital outbreaks. In addition, subsequent studies that assess the correlation between the phenotype and the MRSA genotype are required, as well as characterization of additional features of these clusters, including virulence factors and resistance genes.

\section{Methods}

\section{Sample collection}

This cross-sectional study was conducted at HCIMP in San Luis Potosi, Mexico, after approval by the Research Committee [COFEPRIS 14 CI 24028083] and the Research Ethics Committee of the HCIMP [CONBIOETICA-24-CEI-001-20,160,427]. The registration number was 29-17. Informed consent was obtained from all participants or legal guardians.

The city of San Luis Potosi is located in central Mexico and is the capital of the state of San Luis Potosi. HCIMP provides medical services to mid- and lowincome populations from all over the state; it has 250 beds and 32 beds in the intensive care unit (ICU).

From April 2017 to April 2018, a total of 191 nonrepeated $S$. aureus isolates were obtained from different patients in all hospital wards. These isolates were identified by using the Vitek $2 \mathrm{C}$ (bioMérieux) system and confirmed by PCR amplification of the nuc gene.

Demographic and clinical data, including sex, age, date of hospitalization, type of infection, date of isolation, underlying disease and outcome of infection were collected from medical records. Patients were classified in groups according to their age, as follows: infants (0 to 1year-old), children ( 2 to 10 years old), adolescents (11 to 17 years old), young adults (18 to 35 years old), adults (36 to 60 years old), and seniors (more than 60 years old). An infection was considered as CA when symptoms presented $<48 \mathrm{~h}$ of a patient's hospital admission, in the absence of previous healthcare exposure, whereas 
an infection was considered as HA when occurred $48 \mathrm{~h}$ after patient admission or when it was associated with the following risk factors: hospitalization in an acute care unit for at least $48 \mathrm{~h}$ in the last year, chemotherapy administration, hemodialysis, wound care, enteric nutrition or specialized nursing care 30 days before the infection $[15,42,43]$.

\section{Antimicrobial susceptibility}

Antimicrobial susceptibility testing was performed using Vitek 2C (bioMérieux) and results were interpreted using the Clinical and Laboratory Standards Institute guidelines. Antibiotics tested included benzylpenicillin, clindamycin, erythromycin, levofloxacin, ciprofloxacin, moxifloxacin, rifampin, gentamicin, vancomycin, tetracycline, linezolid, oxacillin, and cefoxitin test [36].

\section{DNA extraction}

Three colonies of an overnight culture were suspended in $100 \mu \mathrm{L}$ of DNase free water and incubated at $94{ }^{\circ} \mathrm{C}$ for $5 \mathrm{~min}$ and $-70{ }^{\circ} \mathrm{C}$ for additional $5 \mathrm{~min}$. Then, tubes were centrifuged at 13,000 rpm for $5 \mathrm{~min}$ and the supernatant was used as DNA template.

\section{nuc and mecA identification}

All $S$. aureus strains were screened by targeting the $n u c$ and mecA genes by multiplex PCR (Table 3) [44, 45]. PCR reactions were performed in a $25 \mu \mathrm{L}$ volume containing $1 \mathrm{x}$ of Buffer $(200 \mathrm{mM}$ Tris- $\mathrm{HCl} \mathrm{pH} \mathrm{8.4,} 500 \mathrm{mM}$ $\mathrm{KCl}), 4 \mathrm{mM}$ of $\mathrm{MgCl}_{2}, 10 \mathrm{pmol}$ of each primer, $200 \mu \mathrm{M}$ of each dNTP's, $1 \mathrm{U}$ of Taq DNA polymerase and bacterial genomic DNA. The PCR conditions were maintained at $95^{\circ} \mathrm{C}$ for $5 \mathrm{~min}$ for initial denaturation followed by 30 cycles of $94^{\circ} \mathrm{C}$ for $30 \mathrm{~s}, 60^{\circ} \mathrm{C}$ for $30 \mathrm{~s}$, and $72{ }^{\circ} \mathrm{C}$ for $30 \mathrm{~s}$. Then, $20 \mu \mathrm{L}$ aliquots of each sample were subjected to electrophoresis on $2 \%$ agarose gel.

\section{SCCmec typing}

Identification of SCCmec types was performed by multiplex PCR using the genomic DNA from each MRSA isolate, according to a previously described method and primers (Table 3) $[46,47]$. DNA amplification was carried out with a 2 min denaturation step at $94{ }^{\circ} \mathrm{C}$, followed by 30 cycles of $60 \mathrm{~s}$ at $94{ }^{\circ} \mathrm{C}$ for denaturation, $60 \mathrm{~s}$ at $55^{\circ} \mathrm{C}$ for annealing, and $60 \mathrm{~s}$ at $72^{\circ} \mathrm{C}$ for extension, and then $5 \mathrm{~min}$ at $72^{\circ} \mathrm{C}$ for final extension. Then, $20 \mu \mathrm{L}$ aliquots of each sample were subjected to electrophoresis on $2 \%$ agarose gel.

\section{Spa-typing}

The $\mathrm{X}$ region of the spa gene of each MRSA isolate was amplified by PCR with the primers $1095 \mathrm{~F}$ and $1517 \mathrm{R}$, as described previously (Table 3) [48]. The amplified products were sequenced, and the results were analyzed
Table 3 PCR primers used in this study

\begin{tabular}{|c|c|c|c|}
\hline Gene & Primer & Primer sequence $5^{\prime} \rightarrow 3^{\prime}$ & Reference \\
\hline \multirow[t]{2}{*}{ nuc } & nuc-F & GCGATTGATGGTGATACGGTT & 44 \\
\hline & nuc- $R$ & AGCCAAGCCTTGACGAACTAAAGC & \\
\hline \multirow[t]{2}{*}{ mecA } & mecA147-F & GTGAAGATATACCAAGTGATT & 45 \\
\hline & mecA147-R & ATGCGCTATAGATTGAAAGGAT & \\
\hline \multirow[t]{2}{*}{ spa } & 1095-F & AGACGATCCTTCGGTGAGC & 48 \\
\hline & $1517-\mathrm{R}$ & GCTTTGCAATGTCATTTACTG & \\
\hline \multirow[t]{10}{*}{ ScCmec } & Type II-F & CGTTGAAGATGATGAAGCG & 46,47 \\
\hline & Type II-R & CGAAATCAATGGTTAATGGACC & \\
\hline & Type-Ilb-F & TAGCTTATGGTGCTTATGCG & \\
\hline & Type-llb-R & GTGCATGATTTCATTTGTGGC & \\
\hline & Type-IVa-F & GCCTTATTCGAAGAAACCG & \\
\hline & Type-IVa-R & CTACTCTTCTGAAAAGCGTCG & \\
\hline & Type IVE-F & CAGATTCATCATTTCAAAGGC & \\
\hline & Type IVE-R & AACAACTATTAGATAATTTCCG & \\
\hline & Type IVc-F & CCTGAATCTAAAGAGATACACCG & \\
\hline & Type IVc-R & GGTTATTTTCATAGTGAATCGC & \\
\hline \multirow[t]{2}{*}{$\operatorname{arcc}$} & $\operatorname{arcC}-\mathrm{F}$ & TTG ATT CAC CAG CGC GTA TTG TC & 50 \\
\hline & $\operatorname{arcC}-\mathrm{R}$ & AGG TAT CTG CTT CAA TCA GCG & \\
\hline \multirow[t]{2}{*}{ aro } & aro-F & ATC GGA AAT CCT ATT TCA CAT TC & \\
\hline & aro-R & GGT GTT GTA TTA ATA ACG ATA TC & \\
\hline \multirow[t]{2}{*}{$g / p$} & glp-F & CTA GGA ACT GCA ATC TTA ATC C & \\
\hline & glp-R & TGG TAA AAT CGC ATG TCC AAT TC & \\
\hline \multirow[t]{2}{*}{ gmk } & gmk-F & ATC GTT TTA TCG GGA CCA TC & \\
\hline & gmk-R & TCATTAACTACAACGTAATCGTA & \\
\hline \multirow[t]{2}{*}{ pta } & pta-F & GTTAAAATCGTATTACCTGAAGG & \\
\hline & pta-R & GACCCTITGTTGAAAAGCTTAA & \\
\hline \multirow[t]{2}{*}{ tpi } & tpi-F & TCGTTCATTCTGAACGTCGTGAA & \\
\hline & tpi-R & TITGCACCTTCTAACAATTGTAC & \\
\hline \multirow[t]{2}{*}{ yqi } & yqi-F & CAGCATACAGGACACCTATTGGC & \\
\hline & yqi-R & CGTTGAGGAATCGATACTGGAAC & \\
\hline
\end{tabular}

using the Ridom Staph Type software version 1.4 (Ridom, GmbH, Wurzburg, Germany [http://spa.ridom. de/index.shtml]) to determine the repeat profile and the spa type of each isolate $[29,49]$.

\section{Dendrogram of MRSA strains}

Dendrogram was constructed based on spa types data using a temporary BioNumerics evaluation license from Applied Maths (version 7.6, bioMérieux).

\section{Multilocus sequence typing}

MLST was performed on six MRSA strains of the spa types $19364(n=4)$ and t895 $(n=2)$. Seven housekeeping genes $(\operatorname{arcC}, \operatorname{aroE}, g l p F, g m k, p t a, t p i$, and $y q i L)$ of $S$. aureus were used for MLST typing (Table 3). PCRs were carried out in $50 \mu \mathrm{l}$ reaction volumes containing $10 \mathrm{ng}$ of 
chromosomal DNA, $10 \mathrm{pmol}$ of each primer, $1 \mathrm{U}$ of Taq DNA polymerase, $5 \mu \mathrm{l}$ of $10 \mathrm{x}$ PCR buffer, and $200 \mu \mathrm{M}$ each of dNTPs. PCR was performed with an initial denaturation at $95^{\circ} \mathrm{C}$ for $5 \mathrm{~min}$, followed by 37 cycles of denaturation at $95^{\circ} \mathrm{C}$ for $30 \mathrm{~s}$, annealing at $55^{\circ} \mathrm{C}$ for 30 $\mathrm{s}$, extension at $72^{\circ} \mathrm{C}$ for $30 \mathrm{~s}$, followed by a final extension step of $72^{\circ} \mathrm{C}$ for $5 \mathrm{~min}$ [50]. After amplification, the PCR products were purified and sequenced by dideoxynucleotides method (3500 Genetic Analyzer, Applied Biosystems). The consensus sequences were assembled, and the allelic profile was matched using the MLST database (https://pubmlst.org/saureus/).

\section{Statistical analysis}

Comparisons between groups was carried using Fisher's exact test or the chi-squared test (for categorical variables) and Student's t test of Mann-Whitney U test (for continuous variables) using Statistical Package for Social Sciences software for Mac OS, version 25.0 (SPSS, IBM, Inc., Chicago, IL, USA). $P$ value $<0.05$ were considered statistically significant.

\section{Supplementary information}

Supplementary information accompanies this paper at https://doi.org/10. 1186/s12866-020-01881-W.

Additional file 1: Table S1. Demographic and clinical characteristics of patients with Staphylococcus aureus infections who died or survived. Table S1 shows the demographic and clinical characteristics of patients with Staphylococcus aureus infections who died or survived.

Additional file 2: Table S2. Minimum Inhibitory Concentration $(\mu \mathrm{g} / \mathrm{mL})$ data for the MRSA strains. Table S2 shows the MIC for each antibiotic for the MRSA strains.

\section{Abbreviations}

S. aureus: Staphylococcus aureus; MRSA: Methicillin-resistant Staphylococcus aureus; HA-MRSA: Healthcare-associated MRSA; CA-MRSA: Communityassociated MRSA; MSSA: Methicillin-sensible Staphylococcus aureus; CC: Clonal complex; ST: Sequence type; WHO: World Health Organization; MLST: Multiple Locus Sequence Typing; PFGE: Pulsed-Field Gel Electrophoresis; NGS: Next Generation Sequencing

\section{Acknowledgments}

We thank to María Anita de Lira Torres, Andrés Flores Santos, and Laura Cerda Ramos, the staff of the Microbiology Laboratory of the HCIMP, for their support in the collection of strains.

We thank to Adriana Rodríguez Martínez and Miriam Briano Macias for their valuable technical support in this project.

\section{Authors' contributions}

CNG conceived the study, acquired clinical data and samples, performed the experiments, interpreted results, and drafted the manuscript. ETM and PNM co-designed and supervised the study and interpreted the results of experiments. DEN and OGC analyzed and interpreted data. DEN and RGA critically revised and edited the manuscript. GMA and LPG analized and interpreted the patient data. All authors have read and approved the manuscript.

\section{Funding}

This work was supported by the Grant 142334 from CONACyT-Salud, Mexico to PNM. CNG was a recipient of a scholarship 443025 from CONACyT, Mexico. The funding agency had no role in the study design, sample collection, data collection and analysis, decision to publish, or preparation of the manuscript.

Availability of data and materials

All data generated or analyzed during this study are included in this published article [and its supplementary information files].

\section{Ethics approval and consent to participate}

This study was approved by the Research Committee [COFEPRIS $14 \mathrm{Cl} 24$ 028 083] and the Research Ethics Committee [CONBIOETICA-24-CEI-00120160427] of the HCIMP. The registration number was 29-17.

Written informed consent was obtained from all participants or legal guardians/parents for those under the age of 16 years.

\section{Consent for publication}

Not applicable.

\section{Competing interests}

The authors declare that they have no competing interests.

\section{Author details}

'Sección de Genómica Médica, Centro de Investigación en Ciencias de la Salud y Biomedicina, Universidad Autónoma de San Luis Potosí, San Luis Potosí, Mexico. 'Laboratorio de Hematología, Facultad de Ciencias Químicas, Universidad Autónoma de San Luis Potosí, San Luis Potosí, Mexico. ${ }^{3}$ Departamento de Farmacología, Facultad de Medicina, Universidad Autónoma de San Luis Potosí, San Luis Potosí, Mexico. ${ }^{4}$ Departamento de Microbiología, Facultad de Medicina, Universidad Autónoma de San Luis Potosí, San Luis Potosí, Mexico. ${ }^{5}$ Unidad de Investigación Biomédica, Instituto Mexicano del Seguro Social, Durango, Mexico. ${ }^{6} \mathrm{Hospital}$ Central "Dr. Ignacio Morones Prieto", San Luis Potosí, Mexico. ${ }^{7}$ Sección de Medicina Molecular y Traslacional, Centro de Investigación en Ciencias de la Salud y Biomedicina, Universidad Autónoma de San Luis Potosí, San Luis Potosí, Mexico. ${ }^{8}$ Laboratorio de Genética, Facultad de Ciencias Químicas, Universidad Autónoma de San Luis Potosí, San Luis Potosí, Mexico.

Received: 29 February 2020 Accepted: 26 June 2020

Published online: 20 July 2020

\section{References}

1. Von Eiff C, Becker K, Machka K, Stammer H, Peters G. Nasal carriage as a source of Staphylococcus aureus bacteremia. N Engl J Med. 2001;344(1):11-6. https://doi.org/10.1056/NEJM200101043440102.

2. Noble WC, Valkenburg HA, Wolters CHL. Carriage of Staphylococcus aureus in random samples of a normal population. Epidemiol Infect. 1967;65(4): 567-73. https://doi.org/10.1017/S002217240004609X.

3. Wertheim HFL, Melles DC, Vos MC, van Leeuwen W, van Belkum A, Verbrugh HA, et al. The role of nasal carriage in Staphylococcus aureus infections. Lancet Infect Dis. 2005;5(12):751-62. https://doi.org/10.1016/ S1473-3099(05)70295-4.

4. Jarraud S, Mougel C, Thioulouse J, Lina G, Meugnier H, Forey F, et al. Relationships between Staphylococcus aureus genetic background, virulence factors, agr groups (alleles), and human disease. Infect Immun. 2002;70(2): 631-41. https://doi.org/10.1128/iai.70.2.631-641.2002.

5. Asadollahi P, Farahani NN, Mirzaii M, Khoramrooz SS, van Belkum A, Asadollahi K, et al. Distribution of the most prevalent spa types among clinical isolates of methicillin-resistant and-susceptible Staphylococcus aureus around the world: a review. Front Microbiol. 2018;9:1-16. https://doi.org/10. 3389/fmicb.2018.00163.

6. International Working Group on the Classification of Staphylococcal Cassette Chromosome Elements (IWG-SCC). Classification of staphylococcal cassette chromosome mec (SCCmec): guidelines for reporting novel SCCmec elements. Antimicrob Agents Chemother. 2009;53(12):4961-7. https://doi.org/10.1128/AAC.00579-09.

7. Wu Z, Li F, Liu D, Xue H, Zhao X. Novel type XII staphylococcal cassette chromosome mec harboring a new cassette chromosome recombinase, CcrC2. Antimicrob Agents Chemother. 2015;59(12):7597-601. https://doi.org/ 10.1128/AAC.01692-15

8. Baig S, Johannesen TB, Overballe-Petersen S, Larsen J, Larsen AR, Stegger M. Novel SCCmec type XIII (9A) identified in an ST152 methicillin-resistant 
Staphylococcus aureus. Infect Genet Evol. 2018;61(January):74-6. https://doi org/10.1016/j.meegid.2018.03.013.

9. Liu J, Chen D, Peters BM, Li L, Li B, Xu Z, et al. Staphylococcal chromosomal cassettes mec (SCCmec): a mobile genetic element in methicillin-resistant Staphylococcus aureus. Microb Pathog. 2016;101:56-67. https://doi.org/10. 1016/j.micpath.2016.10.028

10. Deurenberg RH, Stobberingh EE. The evolution of Staphylococcus aureus. Infect Genet Evol. 2008;8(6):747-63. https://doi.org/10.1016/j. meegid.2008.07.007.

11. Stefani S, Chung DR, Lindsay JA, Friedrich AW, Kearns AM, Westh $\mathrm{H}$, et al. Methicillin-resistant Staphylococcus aureus (MRSA): global epidemiology and harmonisation of typing methods. Int J Antimicrob Agents. 2012;39(4):27382. https://doi.org/10.1016/j.jantimicag.2011.09.030.

12. Lakhundi S, Zhang K. Methicillin-resistant Staphylococcus aureus: molecular characterization, evolution, and epidemiology. Clin Microbiol Rev. 2018; 31(4):e00020-18. https://doi.org/10.1128/CMR.00020-18.

13. Boswihi SS, Udo EE, Monecke S, Mathew B, Noronha B, Verghese T, et al. Emerging variants of methicillin-resistant Staphylococcus aureus genotypes in Kuwait hospitals. PLoS One. 2018;13(4):1-13. https://doi.org/10.1371/ journal.pone.0195933.

14. Lee AS, De Lencastre H, Garau J, Kluytmans J, Malhotra-Kumar S, Peschel A, et al. Methicillin-resistant Staphylococcus aureus. Nat Rev Dis Prim. 2018;4: 18033. https://doi.org/10.1038/nrdp.2018.33.

15. Arias CA, Reyes J, Carvajal LP, Rincon S, Diaz L, Panesso D, et al. A prospective cohort multicenter study of molecular epidemiology and phylogenomics of Staphylococcus aureus bacteremia in nine Latin American countries. Antimicrob Agents Chemother. 2017;61(10). https://doi.org/10. 1128/AAC.00816-17.

16. Challagundla L, Reyes J, Rafiqullah I, Sordelli DO, Echaniz-Aviles G, Velazquez-Meza ME, et al. Phylogenomic classification and the evolution of Clonal complex 5 methicillin-resistant Staphylococcus aureus in the Western Hemisphere. Front Microbiol. 2018;9(AUG):1-14. https://doi.org/10.3389/ fmicb.2018.01901.

17. WHO. Antimicrobial Resistance Global Report on Surveillance. World Health Organization. 2014; Available from: http://apps.who.int/iris/bitstream/ handle/10665/112642/9789241564748_eng.pdf;jsessionid=FAB85B56C04 08C73DBF4ED0A293ECD23? sequence=1. Accessed 15 Nov 2019.

18. Mazi W, Sangal V, Sandstrom G, Saeed A, Yu J. Evaluation of spa-typing of methicillin-resistant Staphylococcus aureus using high-resolution melting analysis. Int J Infect Dis. 2015;38:125-8. https://doi.org/10.1016/j.ijid.2015.05. 002.

19. Strommenger B, Braulke C, Heuck D, Schmidt C, Pasemann B, Nübel U, et al. Spa typing of Staphylococcus aureus as a frontline tool in epidemiological typing. J Clin Microbiol. 2008;46(2):574-81. https://doi.org/10.1128/JCM. 01599-07.

20. Velázquez-Meza ME. Surgimiento y diseminación de Staphylococcus aureus meticilinorresistente Staphylococcus aureus methicillin-resistant: emergence and dissemination. Salud Publica Mex. 2005;47(5):381-7. https://doi.org/10. 1590/s0036-36342005000500009.

21. Bello-Chavolla OY, Bahena-Lopez JP, Garciadiego-Fosass P, Volkow P, GarciaHorton A, Velazquez-Acosta C, et al. Bloodstream infection caused by $S$. aureus in patients with cancer: a 10-year longitudinal single-center study. Support Care Cancer. 2018;26(12):4057-65. https://doi.org/10.1007/s00520018-4275-1.

22. van Hal SJ, Jensen SO, Vaska VL, Espedido BA, Paterson DL, Gosbell IB. Predictors of mortality in Staphylococcus aureus bacteremia. Clin Microbiol Rev. 2012;25(2):362-86. https://doi.org/10.1128/CMR.05022-11.

23. Alpuche-Aranda C, Avila-Figueroa C, Espinoza-De los Monteros L, GómezBarreto D, Santos-Preciado Jl. Antimicrobial sensitivity profile of Staphylococcus aureus at a pediatric hospital: prevalence of resistance to methicillin. Bol Med Hosp Infant Mex. 1989;46:700-4.

24. Macías Hernández AE, Medina Valdovinos H, Gaona Reyes AD, Barret JM, Guerrero Martínez FJ, Ramírez Barba EJ, et al. Estafilococo resistente a meticilina en un hospital general de León Guanajuato. Enferm Infecc Microbiol. 1993;13:123-7.

25. Salvatierra-González R, Benquigui Y. Resistencia antimicrobiana en las Américas. Magnitud del problema y su contención. Washington: OPS; 2000. p. 268. (OPS/HCP/163/2000). ISBN 9275323195 .

26. Garza-González E, Morfín-Otero R, Mendoza-Olazarán S, Bocanegra-Ibarias P,

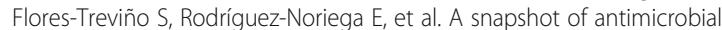
resistance in Mexico. Results from 47 centers from 20 states during a six- month period. PLoS One. 2019;14(3):1-13. https://doi.org/10.1371/journal. pone.0209865.

27. Martínez-Aguilar G. Análisis de genotipos y de los tiempos de duplicación de cepas de Staphylococcus aureus resistente a meticilina aisladas de infecciones nosocomiales y adquiridas en la comunidad. Diss. PhD thesis. México: Universidad de Colima; 2010.

28. Velazquez-Meza ME, Aires De Sousa M, Echaniz-Aviles G, Solórzano-Santos F, Miranda-Novales G, Silva-Sanchez J, et al. Surveillance of methicillin-resistant Staphylococcus aureus in a pediatric hospital in Mexico City during a 7-year period (1997 to 2003): clonal evolution and impact of infection control. J Clin Microbiol. 2004;42(8):3877-80. https://doi.org/10.1128/JCM.42.8.38773880.2004.

29. Ridom GmbH. Ridom SpaServer. Würzburg, Germany. 2005 Available from: https://www.spaserver.ridom.de/ Accessed Feb 2020.

30. Luther M, Parente D, Caffrey A, Daffinee K, Lopes V, Martin E. Clinical and Genetic Risk Factors for Biofilm-Forming Staphylococcus aureus. Antimicrob Agents Chemother. 2018;62(5). https://doi.org/10.1128/AAC.02252-17.

31. Paniagua-Contreras GL, Monroy-Pérez E, Vaca-Paniagua F, et al. Implementation of a novel in vitro model of infection of reconstituted human epithelium for expression of virulence genes in methicillin-resistant Staphylococcus aureus strains isolated from catheter-related infections in Mexico. Ann Clin Microbiol Antimicrob. 2014;13(6). https://doi.org/10.1186/ 1476-0711-13-6.

32. Engelthaler DM, Kelley E, Driebe EM, Bowers J, Eberhard CF, Trujillo J, et al. Rapid and robust phylotyping of spa t003, a dominant MRSA clone in Luxembourg and other European countries. BMC Infect Dis. 2013;13(1):339. https://doi.org/10.1186/1471-2334-13-339.

33. Grundmann H, Aanensen DM, Van Den Wijngaard CC, Spratt BG, Harmsen D, Friedrich AW, et al. Geographic distribution of Staphylococcus aureus causing invasive infections in Europe: A molecular-epidemiological analysis. PLoS Med. 2010;7(1). https://doi.org/10.1371/journal.pmed.1000215.

34. Huenger F, Klik S, Haefner H, Krizanovic V, Koch S, Lemmen SW. P1326 MRSA spa-typing reveals a newly imported hospital endemic strain. Int J Antimicro Ag. 2007;29:S367. https://doi.org/10.1016/s0924-8579(07)71166-4.

35. Kuhn G, Francioli P, Blanc DS. Double-locus sequence typing using clfB and spa, a fast and simple method for epidemiological typing of methicillinresistant Staphylococcus aureus. J Clin Microbiol. 2007;45(1):54-62. https:// doi.org/10.1128/JCM.01457-06

36. CLSI. Performance Standards for Antimicrobial Susceptibility Testing; Twenty-Fifth Informational Supplement. CLSI document M100-S25. Wayne, PA: Clinical and Laboratory Standards Institute; 2015.

37. Liu C, Bayer A, Cosgrove SE, Daum RS, Fridkin SK, Gorwitz RJ, et al. Infectious Diseases Society of America. Clinical practice guidelines by the Infectious Diseases Society of America for the treatment of methicillin-resistant Staphylococcus aureus infections in adults and children. Clin Infect Dis. 2011; 52(3):e18-55. https://doi.org/10.1093/cid/ciq146.

38. Diekema DJ, Pfaller MA, Shortridge D, Zervos M, Jones RN. Twenty-year trends in antimicrobial susceptibilities among Staphylococcus aureus from the SENTRY antimicrobial surveillance program. Open Forum Infect Dis. 2019;6(Suppl 1):S47-53.

39. Partridge SR, Kwong SM, Firth N, Jensen SO. Mobile genetic elements associated with antimicrobial resistance. Clin Microbiol Rev. 2018;31. https:/ doi.org/10.1128/CMR.00088-17.

40. Tenover FC, McDougal LK, Goering RV, Killgore G, Projan SJ, Patel JB, et. al. Characterization of a strain of community-associated methicillinresistant Staphylococcus aureus widely disseminated in the United States. J Clin Microbiol 2006;44:108-118. doi: https://doi.org/10.1128/ JCM.44.1.108-118.2006.

41. Côrtes MF, Botelho AM, Almeida LG, Souza RC, de Lima Cunha O, et al. Community-acquired methicillin-resistant Staphylococcus aureus from ST1 lineage harboring a new SCCmec IV subtype (SCCmec IVm) containing the tetK gene. Infect Drug Resist. 2018;11:2583-92. https://doi.org/10.2147/IDR. S175079.

42. Gerber SI. Describing the methicillin-resistant Staphylococcus aureus epidemic: a public health challenge. Expert Rev Anti-Infect Ther. 2006;4(6): 905-7. https://doi.org/10.1586/14787210.4.6.905.

43. Mekonnen SA, Palma Medina LM, Glasner C, Tsompanidou E, de Jong A, Grasso S, et. al. Signatures of cytoplasmic proteins in the exoproteome distinguish community-and hospital-associated methicillin-resistant Staphylococcus aureus USA300 lineages. Virulence. 2017;8(6):891-907. doi: https://doi.org/10.1080/21505594.2017.1325064. 
44. Brakstad OG, Aasbakk K, Maeland JA. Detection of Staphylococcus aureus by polymerase chain reaction amplification of the nuc gene. J Clin Microbiol. 1992;30(7):1654-60. 1629319.

45. Zhang K, Mcclure J, Elsayed S, Louie T, Conly JM. Novel multiplex PCR assay for characterization and concomitant subtyping of staphylococcal cassette chromosome mec types I to V in methicillin-resistant Staphylococcus aureus. J Clin Microbiol. 2005;43(10):5026-33. https://doi.org/10.1128/JCM.43.10. 5026-5033.2005.

46. Zhang K, McClure J-A, Conly JM. Enhanced multiplex PCR assay for typing of staphylococcal cassette chromosome mec types I to V in methicillinresistant Staphylococcus aureus. Mol Cell Probes. 2012;26(5):218-21. https:// doi.org/10.1016/j.mcp.2012.04.002.

47. Okolie CE, Wooldridge KG, Turner DP, Cockayne A, James R. Development of a new pentaplex real-time PCR assay for the identification of polymicrobial specimens containing Staphylococcus aureus and other staphylococci, with simultaneous detection of staphylococcal virulence and methicillin resistance markers. Mol Cell Probes. 2015;29(3):144-50. https:// doi.org/10.1016/j.mcp.2015.03.002.

48. Shopsin B, Gomez M, Montgomery SO, Smith DH, Waddington M, Dodge $\mathrm{DE}$, et al. Evaluation of protein a gene polymorphic region DNA sequencing for typing of Staphylococcus aureus strains. J Clin Microbiol. 1999;37(11): 3556-63 https://doi.org/10.1128/jcm.37.11.3556-3563.1999.

49. Harmsen D, Claus H, Witte W, Claus H, Turnwald D, Vogel U. Typing of methicillin-resistant Staphylococcus aureus in a university hospital setting by using novel software for spa repeat determination and database management. J Clin Microbiol. 2003;41(12):5442-8. https://doi.org/10.1128/ jcm.41.12.5442-5448.2003.

50. Enright MC, Day NPJ, Davies CE, Peacock SJ, Spratt BG. Multilocus sequence typing for characterization of methicillin-resistant and methicillin-susceptible clones of Staphylococcus aureus. J Clin Microbiol. 2000;38(3):1008-15 https:// doi.org/10.1128/jcm.38.3.1008-1015.2000.

\section{Publisher's Note}

Springer Nature remains neutral with regard to jurisdictional claims in published maps and institutional affiliations.

Ready to submit your research? Choose BMC and benefit from:

- fast, convenient online submission

- thorough peer review by experienced researchers in your field

- rapid publication on acceptance

- support for research data, including large and complex data types

- gold Open Access which fosters wider collaboration and increased citations

- maximum visibility for your research: over $100 \mathrm{M}$ website views per year

At $\mathrm{BMC}$, research is always in progress.

Learn more biomedcentral.com/submissions 